\title{
Diego de San Pedro, Petit traité de Arnalte et Lucenda
}

\section{Dario Cecchetti}

\section{(2) OpenEdition}

\section{Journals}

\section{Edizione digitale}

URL: http://journals.openedition.org/studifrancesi/32962

DOI: 10.4000/studifrancesi.32962

ISSN: 2427-5856

\section{Editore}

Rosenberg \& Sellier

\section{Edizione cartacea}

Data di pubblicazione: 1 décembre 2005

Paginazione: 625

ISSN: 0039-2944

\section{Notizia bibliografica digitale}

Dario Cecchetti, «Diego de San Pedro, Petit traité de Arnalte et Lucenda», Studi Francesi [Online], 147

(XLX | III) | 2005, online dal 30 novembre 2015, consultato il 19 avril 2021. URL: http://

journals.openedition.org/studifrancesi/32962 ; DOI: https://doi.org/10.4000/studifrancesi.32962

\section{Questo documento è stato generato automaticamente il 19 avril 2021.}

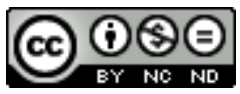

Studi Francesi è distribuita con Licenza Creative Commons Attribuzione - Non commerciale - Non opere derivate 4.0 Internazionale. 


\title{
Diego de San Pedro, Petit traité de Arnalte et Lucenda
}

\author{
Dario Cecchetti
}

\section{NOTIZIA}

DIEGO DE SAN PEDRO, Petit traité de Arnalte et Lucenda, édition établie et annotée par VÉRONIQUE DUCHÉ-GAVET, Paris, Champion («Textes de la Renaissance», 82), pp. L+238.

1 Abbiamo qui offerta agli studiosi un'importante testimonianza dell'ispanismo nella Francia del Rinascimento, in particolare degli apporti del romanzo spagnolo alla prosa narrativa francese del Cinquecento. Si tratta della traduzione che Nicolas Herberay des Essarts condusse a termine nel 1539 (ma qui viene pubblicata l'edizione del 1546) del Tractado de amores de Arnalte y Lucenda (1491) di Diego de San Pedro, uno degli autori spagnoli più letti e tradotti in Europa nel XVI secolo. Des Essarts, fortemente influenzato dalla cultura spagnola (abbiamo notizia di una sua traduzione dell'Electra di Sofocle, sulla base di una versione spagnola), traduce qui una novela sentimental che segna il passaggio dalla tradizione narrativa medievale a quella rinascimentale, per l'intermediario di testi classici, ovidiani in particolare, e italiani, quali la Fiammetta boccacciana o la De duobus amantibus historia di Enea Silvio Piccolomini. Il Tractado di Diego de San Pedro avrà un'ulteriore fortuna europea attraverso traduzioni in italiano, in inglese, in tedesco e in fiammingo, fino alla metà del Seicento, come si evince dal repertorio dei rifacimenti in queste lingue, oltre che in francese, ricostituito da V. Duché-Gavet (pp. XXXIII-XL). La versione di Des Essarts viene qui pubblicata con l'originale spagnolo in basso pagina e con un'accurata annotazione. Soprattutto, l'editore tratta il documento come una testimonianza linguistica, e in questa prospettiva è concepito l'accurato glossario, redatto secondo il protocollo stabilito da C. Buridant per la stesura di lessici del francese préclassique. 